\title{
Estrutura cristalina de chalconas contendo N-heterociclos e investigação da supramoleculariedade através de superfície de Hirshfeld.
}

C. M. D. S. Junior ${ }^{\text {a }, ~ C . ~ M . ~ B . ~ d e ~ A z e v e d o ~ a, ~ J . ~ C . ~ P e s s o ̂ a ~ a ~, ~ A . ~ S . ~ d e ~ S o u z a ~}{ }^{\text {a }}$, S. Pinheiro a , M. C. R. Freitas ${ }^{\mathrm{b}}$.

Instituto de Química, Universidade Federal Fluminense, Niterói, Brazil. Instituto de Física, Universidade Federal Fluminense, Niterói, Brazil.

Chalconas pertencem à classe dos compostos flavonoides. Quimicamente caracterizamse por apresentarem subunidade C6-C3-C6, genericamente $\mathrm{Cn}$, onde $\mathrm{n}=$ número de átomos ligados, em que $n=3$ corresponde a uma cetona, alfa, beta insaturada. Podem ser de origem natural ou sintética. Foram realizados estudos estruturais correlacionando-os com propriedades anticancerígenas, sendo que a substituição do anel C6 por anéis heterocíclicos, uma boa estratégia na busca por agentes anticancerígenos ${ }^{1}$. Neste trabalho analisaremos as estruturas de três chalconas sintéticas, cujas unidades assimétricas correspondentes às moléculas apresentamse na Figura 1. Os compostos pertencem ao sistema cristalino, monoclínico (CHALC01 e CHALC02) e ortorrômbico (CHALC10), com grupos espaciais Pc, P2 ${ }_{1} / c$ e P2 $2_{1} 2_{1} 2_{1}$ respectivamente, todas $\operatorname{com} \mathrm{z}=4$.
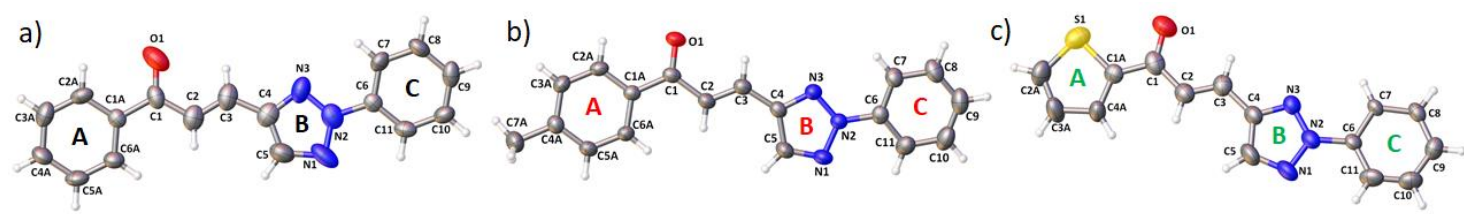

Figura 1: Unidades assimétricas dos compostos a) CHALC01 B) CHALC02 e C) CHALC10.

Pode-se observar da Figura 1, que todas as chalconas apresentaram conformação s-cis, o que segundo Lawrence e colaboradores, influencia na atividade citotóxica ${ }^{2}$. As distâncias das ligações C-C presente no anel A são na média 1,373(9); 1,385(2) e 1,370(8) Å respectivamente para CHALC01, 02 e 10. Essas distâncias são intermediárias entre ligações simples C-C $(1,54 \AA)$ e ligações duplas $\mathrm{C}=\mathrm{C}(1,34 \AA)^{3}$, evidenciando o caráter aromático do anel. Mesma tendência de aromaticidade foi observada para os valores das distâncias de ligação nos anéis triazólicos B, 1,336(9); 1,398(2) e 1,353(8) ^ e fenil C, 1,372(9); 1,380(3) e 1,373(8) ^. Os anéis aromático $\mathrm{A}$ e $\mathrm{B}$ conectados pelo grupamento alifático apresentam pequenos ângulos de torção, iguais a 6,2(6), 4,6(1) e 12,0(5) ${ }^{\circ}$ respectivamente para as chalconas 01,02 e $10 . \mathrm{O}$ pequeno desvio de planaridade pode evidenciar uma leve deslocalização eletrônica entre os anéis. A aromaticidade por sua vez contribui para interações intermoleculares do tipo $\mathrm{C}-\mathrm{H} \cdots \pi$ presente nos sólidos, como ilustrado na Figura 2a) para CHALC01. Além destas interações, estão presentes ligações de hidrogênio não clássicas, como ilustrado na Figura 2b) e c) para CHALC02 e 10. Espera-se que a descrição de parâmetros estruturais de um conjunto de chalconas, juntamente com futuros resultados biológicos, possam contribuir para a racionalização de eficientes agentes anticancerígenos desta classe de compostos. 


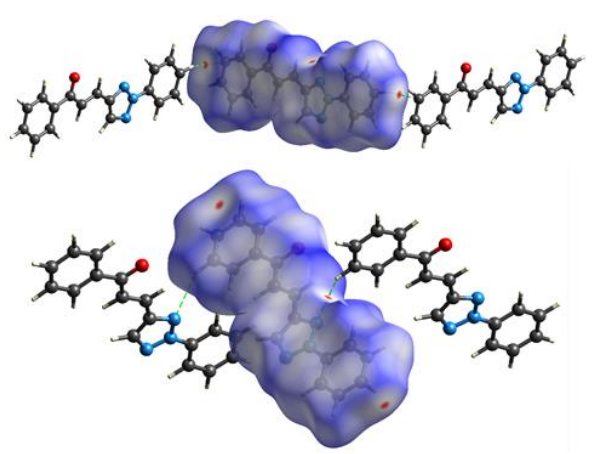

a)

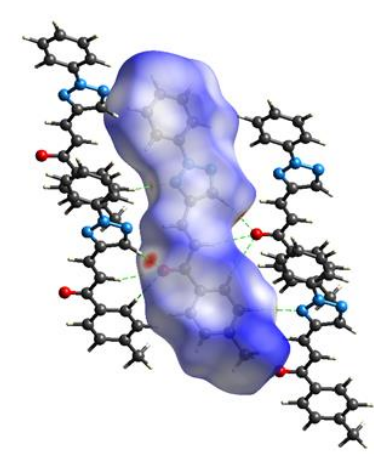

b)

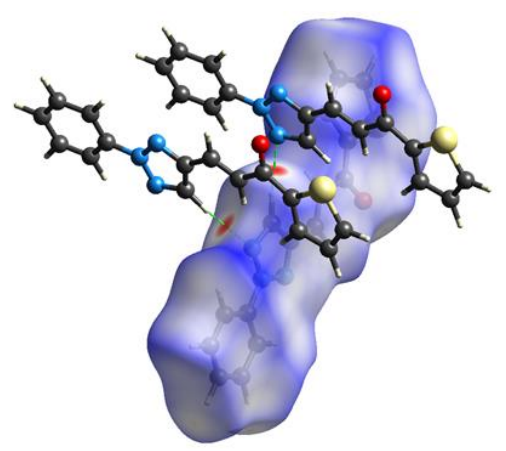

c)

Figura 2: HS em dnorm para a) CHALC01 B) CHALC02 e C) CHALC10.

${ }^{1}$ Kamal, A.; at al.; Eur. J. Med. Chem. 2011, 46, 3820

${ }^{2}$ Ducki, S.; at al.; Med. Chem. 1998, 8, 1051.

${ }^{3}$ International Tables for Crystallography, v. C, p. 790-811, 2006. 